\title{
Protective Effect of Ischemic Preconditioning on Hepatic Ischemia-Reperfusion Injury in Rats
}

\author{
Naoki Hashimoto \\ Department of Surgery, Kinki University, Osaka, Japan \\ Email: gojigen000@gmail.com
}

Received 18 January 2015; accepted 1 February 2015; published 5 February 2015

Copyright (C) 2015 by author and OALib.

This work is licensed under the Creative Commons Attribution International License (CC BY). http://creativecommons.org/licenses/by/4.0/

(c) (i) Open Access

\begin{abstract}
Aim: Ischemic preconditioning (IPC) protects tissue against ischemia and reperfusion (I/R) injury. The aim of this study was to examine the impact of IPC on protection of hepatocytes after prolonged I/R injury. Methods: Twenty-four Wistar rats were randomly divided into ischemic preconditioning group (IP), ischemia/reperfusion group (IR) and sham operation group (SO). A model of partial liver ischemia/reperfusion was used, in which rats were subjected to liver ischemia for 90 min prior to reperfusion. The animals in the IP group underwent ischemic preconditioning for $10 \mathrm{~min}$ prior to the ischemia/reperfusion challenge. After $3 \mathrm{~h}$ of reperfusion, serum and liver tissue in each group were collected to detect the level of serum ALT, AST, HA, MDA and liver histopathology. Results: Compared with IR group, IP group showed a significantly lower ALT, AST, HA and MDA level in $3 \mathrm{~h}$. Proliferation index (PI) was significantly increased in IP group compared with IR group. Conclusion: Ischemic preconditioning can protect liver cells against ischemia/reperfusion injury, which may be related to cell proliferation during early ischemic reperfusion.
\end{abstract}

\section{Keywords}

Ischemic Preconditioning (IPC), Ischemia/Reperfusion (I/R), Proliferation Index (PI), Reactive Oxygen Species (ROS), Hepatic Ischemia

Subject Areas: Gastroenterology \& Hepatology

\section{Introduction}

Hepatic ischemia/reperfusion (IR) injury is an important clinical problem occurring in hepatic resection or liver transplantation. Ischemic preconditioning (IP) has been proven to be an effective method protecting the liver against ischemia/reperfusion injury [1]. Many mechanisms are associated with this phenomenon [2], but some 
are still unclear.

In what appears to be an analogous phenomenon to ischemic preconditioning against IR injury, a small, nonlethal dose of carbon tetrachlodide (CCL4) protects the liver against a second massively hepatotoxic dose administered 24 hours later [3]. This conditioning phenomenon with CCL4 is associated with cell cycle entry.

Previous studies showed that the analogous conditioning phenomenon induced by carbon tetrachloride (CCL4) was related to hepatocellular proliferation [4].

Whether IP promotes hepatocellular regeneration remains unknown.

This study was to assess the effect of IP on cell regeneration and to explore the possible mechanism of IP protection.

\section{Material and Methods}

Adult male Wistar rats, weighing 250 to $300 \mathrm{~g}$ were used in all experiments. The animals were provided with regular chow (Nihon Clea Shizuoka Japan) and water ad libitum, and were housed in a 12-h dark/12-h light cycle, pathogen-free environment at the Kinki University Animal Faculty.

All rats were treated according to the guidelines on animal experimentation set out by the National Institutes of Health (Bethesda, MD, USA).

\subsection{Animal Model}

The rats were randomly divided into 3 groups of 8 rats each; sham operated (sham) group, ischemia/reperfusion (I/R) group, ischemic preconditioning plus ischemia/reperfusion (IPC) group. Liver I/R injury was induced as follows. Rats were anesthetized with sodium pentobarbital (50 mg/kg intraperitoneally). A midline laparotomy was performed. An atraumatic clip was used to interrupt blood supply to the left lateral and median lobes of the liver.

After 90 min of partial hepatic ischemia, the clip was removed to initiate hepatic reperfusion. Sham groups rats underwent the same protocol without vascular occlusion. But in IPC group rats, before the procedure of ischemia/reperfusion, the left lateral and median lobes of the liver were subjected to $10 \mathrm{~min}$ ischemia followed by 10 min reperfusion. Three hours after liver reperfusion, all rats were sacrificed and blood and liver samples were collected for analysis.

\subsection{Serum Liver Function, Hyaluronic Acid Assay and MDA}

Serum alanine aminotransferase (ALT) and aspartate aminotransferase (AST) levels were measured using commercial kits by a Hitachi Automatic Biochemical Analyzer. Determination of serum hyaluronic acid was performed by a sandwich binding protein assay. MDA was assayed by the measurement of thiobarbituric acidreactive substances (TBARS) levels at $532 \mathrm{~nm}$. Results were expressed as nmol/mg protein.

\subsection{Hepatic Histology and PCNA Immunohistochemistry}

The severity of liver injury was determined from hepatic histology. Consecutive sections from paraffin-embedded liver were cut for haematoxylin and eosin staining for evaluation of necrosis and proliferating cell nuclear antigen (PCNA) immunohistochemistry. PCNA immunohistochemistry was performed with Santa Cruz ImmunoCruz Staining System Kit. PCNA-positive staining nuclei were counted in 5 high-power fields (magnification $\times 40$ ), and the results were expressed as a percentage of total number of hepatocyte nuclei.

\subsection{Statistical Analysis}

Data were expressed as mean \pm SD. The statistical significance of differences between groups were analyzed using the one-way analysis of variance (ANOVA). The P values less than 0.05 was considered statistically significant.

\section{Results}

1) Serum ALT, AST, and HA levels (Table 1) 
Table 1. Effect of IPC, I/R and sham on serum ALT, AST, HA and MDA levels.

\begin{tabular}{ccccc}
\hline Groups & ALT (U/L) & AST (U/L) & HA (mg/L) & MDA (nmol/mL) \\
\hline Sham & $40 \pm 10$ & $35 \pm 10$ & $20 \pm 10$ & $1.5 \pm 0.6$ \\
I/R & $6710 \pm 1400^{\#}$ & $12000 \pm 1700^{\#}$ & $70 \pm 30^{\#}$ & $3.8 \pm 1.1^{\#}$ \\
IPC & $4200 \pm 1000^{* \#}$ & $6800 \pm 2400^{* \#}$ & $30 \pm 10^{*}$ & $2.0 \pm 0.6^{*}$ \\
\hline
\end{tabular}

${ }^{\#} \mathrm{P}<0.05$ vs sham group; ${ }^{*} \mathrm{P}<0.05$ vs I/R group.

After 90 min of hepatic ischemia and $3 \mathrm{~h}$ of reperfusion, serum ALT and ALT levels were significantly increased in I/R group, as compared with sham group $(\mathrm{P}<0.05)$. However, in IPC group, serum ALT and AST levels were markedly reduced when compared with $\mathrm{I} / \mathrm{R}$ group $(\mathrm{P}<0.05)$. Serum levels of hyaluronic acid were also significantly increased in $\mathrm{I} / \mathrm{R}$ group compared with sham group $(\mathrm{P}<0.05)$. In IPC group, serum hyaluronic acid levels were markedly lower than in $\mathrm{I} / \mathrm{R}$ group $(\mathrm{P}<0.05)$.

2) Serum MDA level (Table 1)

Serum level of MDA, a marker of oxidative stress, was significantly higher in I/R group compared with sham group $(\mathrm{P}<0.01)$. However, serum MDA level in IPC group was markedly decreased as compared with $\mathrm{I} / \mathrm{R}$ group $(\mathrm{P}<0.05)$.

3) Pathological changes (Figure 1)

The ischemic lobes in I/R group revealed disorderly liver sinusoids, enlarged and congested with many red blood cells, their lining endothelial cells degenerated, necrotized and sloughed off, exposing parenchymal cells immediately to blood, as well as multiple and extensive hepatocellular necrosis and massive infiltration of neutrophils. However, IPC group showed good preservation of lobular architecture, with less sinusoidal lining endothelial cells swelled, necrotized and sloughed off and few hepatocellular necrosis and neutrophils infiltration as well.

4) PCNA labeling index (Figure 2)

The number of PCNA positive nuclei was significantly increased in preconditioned $(0.83 \pm 0.06)$ versus unpreconditioned group $(0.61 \pm 0.04)$.

\section{Discussion}

Hepatic ischemia/reperfusion can lead to liver cells (i.e., parenchymal and sinusoidal cells) damage and dysfunction. Ischemic pre-conditioning is extensively documented to reduce $\mathrm{I} / \mathrm{R}$ injury in a variety of organs including liver [5]. In our study, we demonstrated that IPC could attenuate hepatic I/R injury, indicated by reduced serum ALT and AST levels and improved tissue pathologic alteration as compared with $\mathrm{I} / \mathrm{R}$ group. Hyaluronic acid (HA) is produced mainly by fibroblast and other specialized connective tissue cells, and removed from circulation by specific receptors present in sinusoidal cell (SEC) of the liver. HA uptake reflects the damage of SEC and serum HA levels were used as a noninvasive indicator of SEC damage [6]. Our experiment showed that the increase of serum HA levels was markedly prevented in IPC group as compared with I/R group and sinusoidal endothelial pathological alteration also significantly improved, suggesting that IPC was not limited to parenchymal cells but ameliorated sinusoidal cells dysfunction during I/R injury.

Reative oxygen species (ROS) have been implicated in the pathogenesis of ischemia/reperfusion injury. ROS is involved in the I/R injury. Serum MDA, the product of lipid peroxidation, was significantly increased following I/R compared with sham group. In IPC group, serum MDA was markedly lowered compared with I/R group.

The result is in agreement with the reports of Cavalieri et al. [7] Peralta et al. showed that IPC could block the Xanthine oxidase pathway of ROS generation, thus providing protection against liver I/R injury [8].

The most novel and potentially important finding of the present work is that all preconditioned liver sections revealed striking hepatocyte nuclear variability and mitoses after subsequent IR. These were not features in unpreconditioned livers subjected to identical IR. This observation led us to postulate that a preconditioning stimulus could drive quiescent hepatocytes to enter the cell cycle. To better quantify the apparent regenerative response stimulated by preconditioning, we stained liver sections for PCNA, which is synthesized in G1 and S phase of the cell cycle so that prominent nuclear localization is found in proliferating hepatocytes [9]. In preconditioned rat, PCNA staining of nuclei was clearly evident within 3 hours of the onset of reperfusion after 


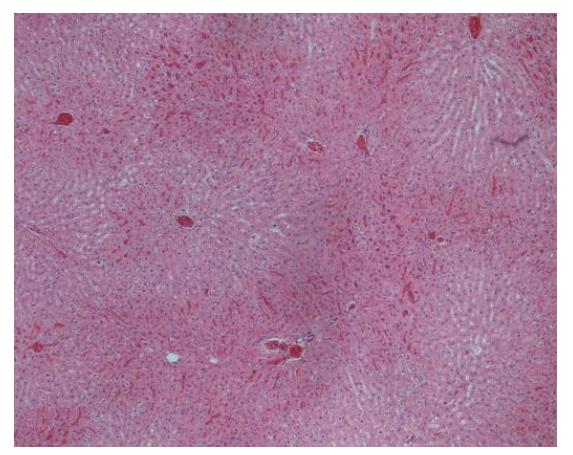

IPC group

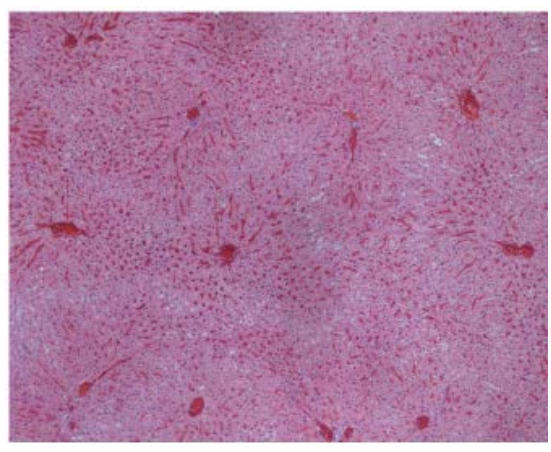

I/R group

Figure 1. Liver tissue from I/R and IPC group.

PCNA positive staining

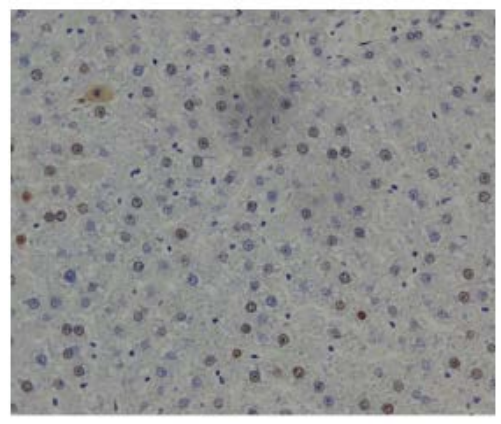

IPC group
PCNA positive staining

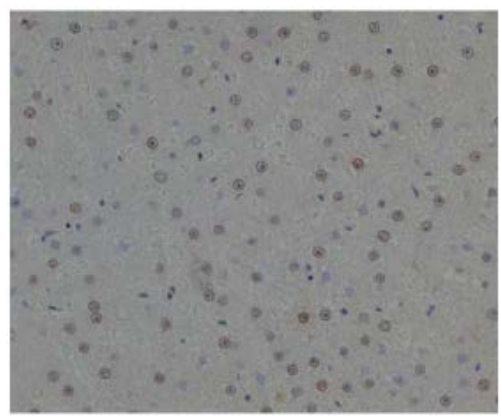

I/Rgroup

Labeling index $0.83 \pm 0.06$

Figure 2. Proliferating cell nuclear antigen (PCNA) staining in I/R group and IPC group.

90 minutes of ischemia. These observations suggest that ischemic preconditioning primes hepatocytes to enter the cell cycle early, hence setting up a regenerative response to diminish or compensate for subsequent hepatocyte injury induced by prolong ischemia and IR. Proliferation index (PI) increased significantly at $3 \mathrm{~h}$ of reperfusion in IPC group compared with I/R group. The finding of the present work is that IPC could promote liver cell proliferation during early ischemic reperfusion, which is possibly related to IPC protection. Zhang et al. [10] showed that proliferating liver cells can resist IR injury. The mechanism of cellular proliferation involved in IPC are still obscure. The mechanisms may be related to the fact that IP activates the p38MAPK pathway [11], leading to activation of regulatory proteins and production of DNA synthetic proteins, such as cyclinD1 and interleukin-6 (IL-6) [12]. The p38MAPK pathway is an important signaling pathway involved in IP. Blockade of the p38MAPK pathway can lead to loss of protection of IP [13].

\section{Conclusion}

Ischemic preconditioning can protect liver cells against ischemia/reperfusion injury, which may be related to cell proliferation during early ischemic reperfusion. However, their underlying regulatory pathway and biological role remain unclear.

\section{References}

[1] Montalvo, E.E., Escalante, T., Pina, E., et al. (2008) Factors in the Pathophysiology of the Liver Ischemia-Reperfusion Injury. Journal of Surgical Research, 147, 153-159. http://dx.doi.org/10.1016/j.jss.2007.06.015

[2] DeOliveira, M.L., Graf, R. and Clavien, P.A. (2008) Ischemic Preconditioning: Promises from the Laboratory to Patients-Sustained or Disillusioned? American Journal of Transplantation, 8, 489-491. http://dx.doi.org/10.1111/j.1600-6143.2007.02091.x 
[3] Mehendale, H.M., Roth, R.A., Gandolfi, A.J., et al. (1994) Novel Mechanisms in Chemically Induced Hepatotoxicity. FASEB Journal, 8, 1285-1295.

[4] Cai, Z.W. and Mehendale, H.M. (1991) Protection from CC4 Toxicity by Prestimulation of Hepatocellular Regeneration in Partially Hepatectomized Gerbils. Biochemical Pharmacology, 42, 633-644. http://dx.doi.org/10.1016/0006-2952(91)90327-2

[5] Peralta, C., Serafin, A., Fernandez-Zabalegui, L., Wu, Z.Y., et al. (2003) Liver Ischemic Preconditioning: A New Strategy for the Prevention of Ischemia-Reperfusion Injury. Transplantation Proceedings, 35, 1800-1802. http://dx.doi.org/10.1016/S0041-1345(03)00571-2

[6] Reinders, M.E., van Wagensveld, B.A., van Gulik, T.Y., et al. (1996) Hyaluronic Acid Uptake in the Assessment of Sinusoidal Endothelial Cell Damage after Cold Storage and Normothermic Reperfusion of Rat Livers. Transplant International, 9, 446-453. http://dx.doi.org/10.1111/j.1432-2277.1996.tb00987.x

[7] Cavalieri, B., Perrelli, M.G., Yang, J.J., et al. (2002) Ischemic Preconditioning Attenuates the Oxidant-Dependent Mechanisms of Reperfusion Cell Damage and Death in Rat Liver. Liver Transplantation, 8, 990-999. http://dx.doi.org/10.1053/jlts.2002.35549

[8] Peralta, C., Serafin, A., Fernandez-Zabalegui, L., et al. (2002) Ischemic Preconditioning: A Defense Mechanism against the Reactive Oxygen Species Generated after Hepatic Ischemia Reperfusion. Transplantation, 73, $1203-1211$. http://dx.doi.org/10.1097/00007890-200204270-00004

[9] Bravo, R. and Macdonald-Bravo, H. (1991) Existence of Two Populations of Cyclin/Proliferating Cell Nuclear Antigen during the Cell Cycle: Association with DNA Replication Sites. Journal of Cell Biology, 19, 29-33.

[10] Zhang, B.H., Gong, D.Z. and Mei, M.H. (1999) Protection of Regenerating Liver after Partial Hepatectomy from Carbon Tetrachloride Hepatotoxicity in Rats: Role of Hepatic Stimulator Substance. Journal of Gastroenterology and Hepatology, 14, 1010-1017. http://dx.doi.org/10.1046/j.1440-1746.1999.01992.x

[11] Schauer, R.J., Gerbes, A.L., Vonier, D., et al. (2003) Induction of Cellular Resistance against Kupffer Cell-Derived Oxidant Stress: A Novel Concept of Hepatoprotection by Ischemic Preconditioning. Hepatology, 37, 286-295. http://dx.doi.org/10.1053/jhep.2003.50064

[12] Cai, F.G., Xiao, J.S. and Ye, Q.F. (2006) Effects of Ischemic Preconditioning on Cyclin D1 Expression during Early Ischemic Reperfusion in Rats. World Journal of Gastroenterology, 12, 2936-2940.

[13] Carini, R., De Cesaris, M.G., Splendore, R., et al. (2001) Signal Pathway Involved in the Development of Hypoxic Preconditioning in Rat Hepatocytes. Hepatology, 33, 131-139. http://dx.doi.org/10.1053/jhep.2001.21050 
Scientific Research Publishing (SCIRP) is one of the largest Open Access journal publishers. It is currently publishing more than 200 open access, online, peer-reviewed journals covering a wide range of academic disciplines. SCIRP serves the worldwide academic communities and contributes to the progress and application of science with its publication.

Other selected journals from SCIRP are listed as below. Submit your manuscript to us via either submit@scirp.org or Online Submission Portal.
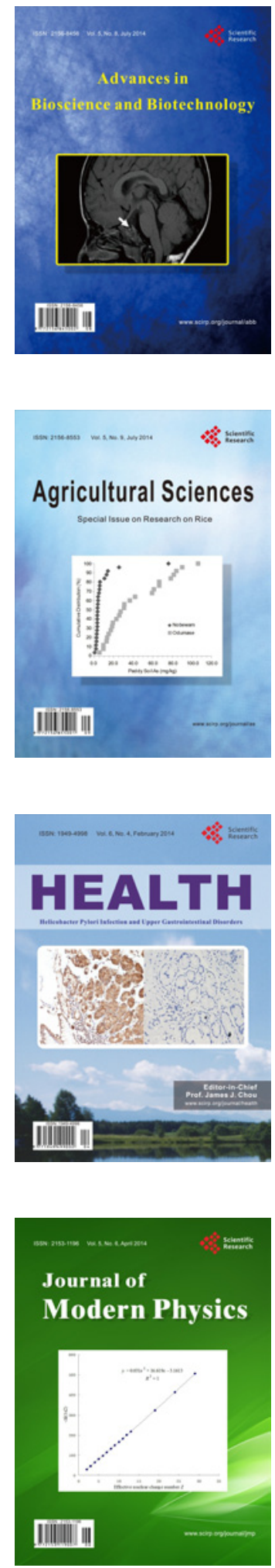
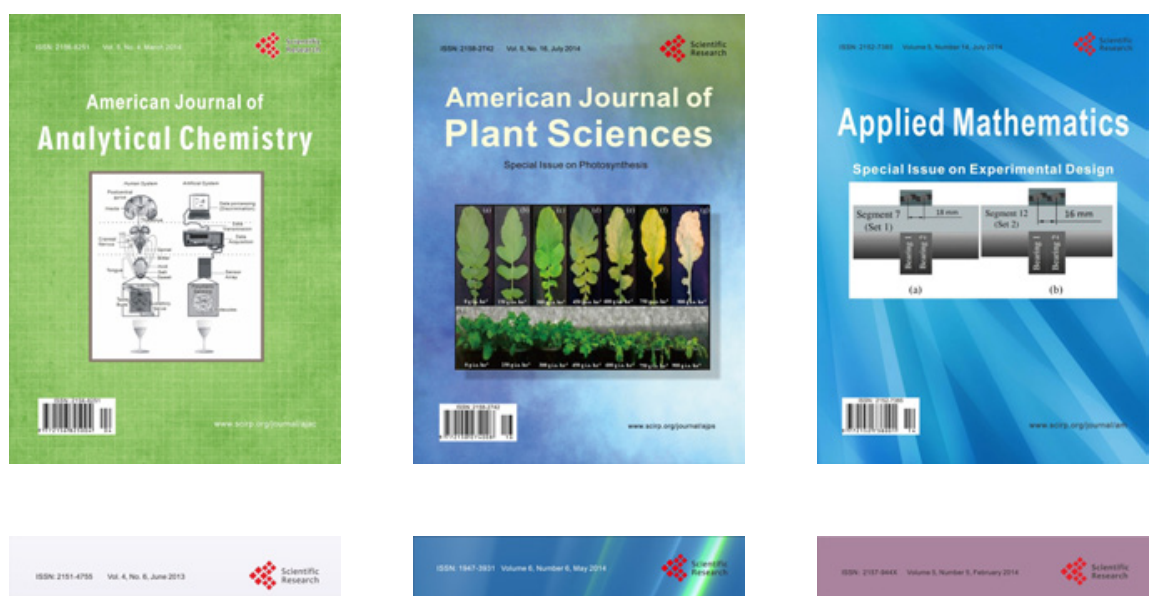

Creative Education
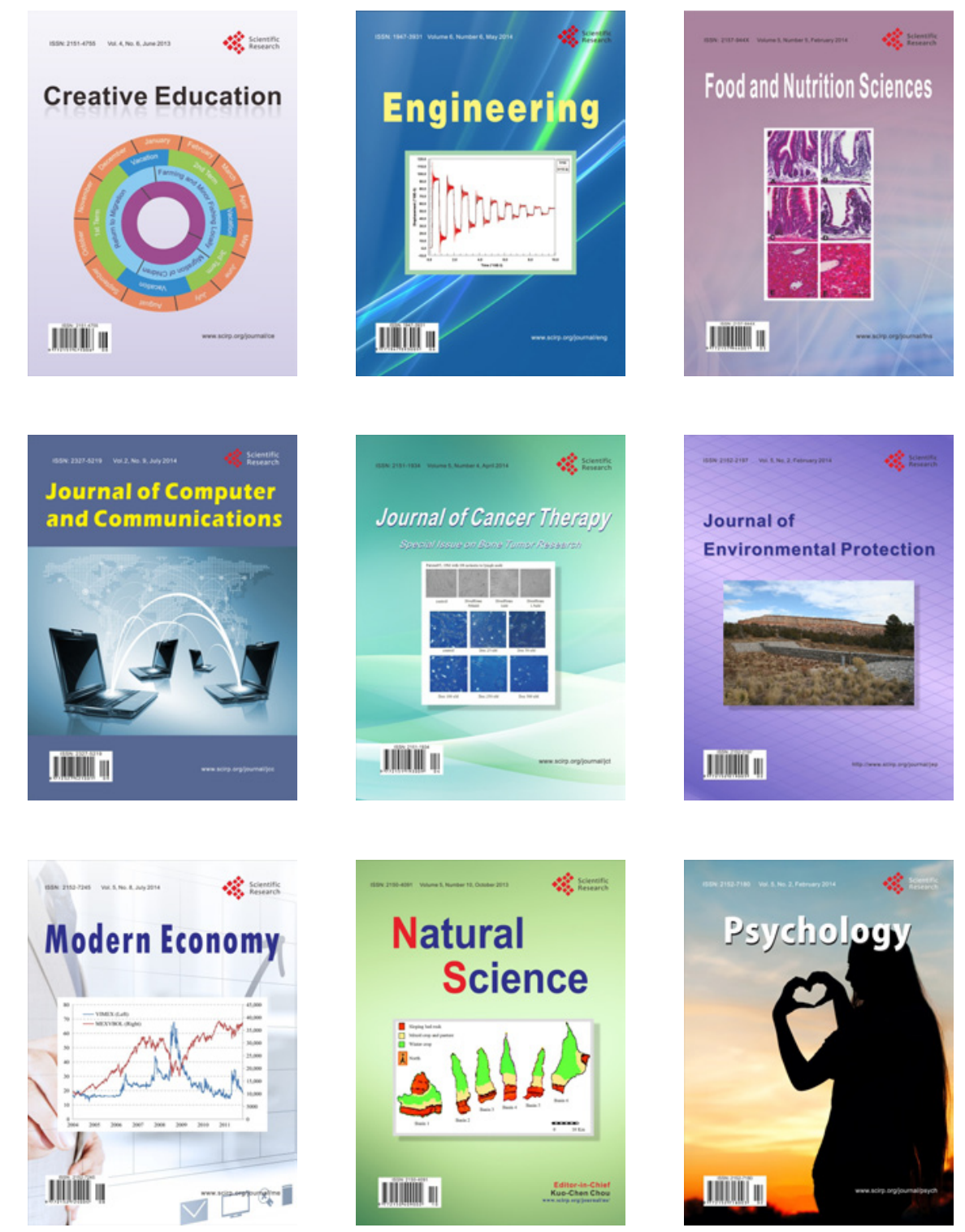